\title{
A Structural Model of an Integrated Information System for Health Promoting Behaviors after Radical Prostatectomy
}

\author{
Seong-Ran Lee \\ Department of Medical Information, Kongju National University \\ lsr2626@naver.com
}

\begin{abstract}
This research is to investigate a structural model of an integrated information system for health promoting behaviors after radical prostectomy. The subjects of this paper were 142 patients who had visited a general hospital located in Metropolitan area. The pairwise t-test was done to compare the before and after application effect of health practice rate after radical prostatectomy. The results of this study are as follows. First, the response rate(29.6\%) of experimental group was statistically significantly higher than the response rate $(26.8 \%)$ in the 50 to 59 years old $\left(\chi^{2}=10.27, p<.05\right)$. Second, for soybean intake, positive change of health behaviors behaviors diminished the progression rate of prostate cancer( $31.24 \pm 0.35, t=-0.57, p=.000)$. Third, this paper found that the health promoting behaviors in prostate cancer patients was increased by 69.2-73.6\% compared with the previous status. This study will contribute to reducing prostate cancer patients from prostatitis to prostate cancer in the future.
\end{abstract}

Keywords: An integrated information system, Health promoting behaviors, Radical prostatectomy

\section{Introduction}

Prostate cancer is rapidly increasing in Korea. It is the second most prevalent solid tumor diagnosed in Western Europe [1-3]. Prostate cancer is also the most common type of non-skin cancer diagnosed in American Men [4,5]. One in 6 men will be diagnosed with prostate cancer over the course of his lifetime. The Prostate Cancer Foundation says that prostate cancer is also the second most common cause of cancer death in men, behind only lung cancer in the United States [6,7]. WHO officials say about two hundred fifty thousand people die each year from prostate cancer. They say the death rate is about ten times higher in Europe and North American than in Asia The National Cancer Institute estimates that there will be 238,720 new cases and 29,720 deaths due to prostate cancer in the United States during the year 2013 [8-10].

Prostate cancer incidence rates increased by $19.6 \%$ per year between 2007 and 2013. It appeared the increase due to detection of early-stage disease. There was no increase in the incidence rate of metastatic cancer. Incidence rates varied widely among the SEER program areas. In 2013 from 352.8 per 100,000 in Connecticut to 719.4 in Seattle. Radical prostatectomy rates tripled between 2007 and 2013 in the SEER areas as a whole. Among men aged 70-79, the rate of prostatectomy increased by nearly $43 \%$ per year. There was a five-fold variation among SEER areas in radical prostatectomy rates in 2009, with a low of 74.8 per 100,000 in Connecticut and a high of 362.5 in Seattle [11-13]. Increases in rates of prostate cancer incidence and prostate surgery have occurred in the United States without clear evidence that screening and prostatectomy are effective in reducing mortality. Moreover, much of the growth in incidence and radical prostatectomy rates have occurred among older men, who appear least likely to benefit from early detection and surgery of occult prostate cancer. However, patients who underwent radical retropubic prostatectomy have increased risk of developing inguinal hernia $[14,15]$. 
In order to solve the urgent problem, we should look for the practical plans. However, there were few studies to deal with effect of an integrated information system to improve health behaviors after prostatectomy so far. We also don't have any national program about it $[16,17]$. Therefore, the information system including prostatectomy is urgently needed to control the increasing prevalence of prostate cancer and produce its related desirable outcomes.

This study is to identify variables which have influence on establishing successful integrated information system and relationships among these variables and to find a success model and variables in establishing integrated information system in patients with prostate cancer. Precedent and other studies related to this study were reviewed and on the basis of these reviews, success variables were found to establish integrated information system. Thus, this paper is to design a structural model of an integrated information system to improve health promoting behaviors after radical prostatectomy. That is, this paper was attempted to estimate the effect of it on the change of health status for health improvement in prostatectomy patients through development of an integrated information system.

This study will contribute to reducing prostate cancer patients from prostatitis to prostate cancer in the future. This system will demonstrate the dramatic effect of intervention programs to promote physical and mental health status. This system is interactive and accessible to anyone in the world. It is expected that this integrated information system will contribute to prostate patients' health promoting behaviors and allow researchers and professionals to share information on health promotion behaviors. In conclusion, an improved information system will contribute to prevent disease in patients with prostate cancer.

\section{Materials and Methods}

\subsection{Structure of Database System}

This paper is to provide for an efficient information system from strategic targets to solution method. In the first stage, this step defines strategic targets and how to achieve them within the organization. In the second stage, it is to identify the functional elements of successful information system and gather the information. In the third stage, implementation stage, where a preliminary program is to be applied and evaluated in the field has been implemented. It also demonstrated the need to separate data from its applications using it. When the health practice has finished its work on processes and data classes, it can explore the functions and effects of the information system [Figure 1].

\subsection{Study Materials}

Study participants were patients who were treated with prostatectomy at least 5 months ago by urology of a general hospital in Metropolitan area. The data were collected by interview and self-administered questionnaire from April 21 through May 23, 2014.

This program was totally consisted 142 persons, it has been divided into two parts. The experimental group of 71 patients which was assigned as group with information intervention, while the control group of 71 patients was assigned as group with no information intervention. The two groups are compared to know the difference of changes which affects health promoting behaviors. On the other hand, the evaluation of patient's satisfaction on the integrated information system through information intervention was performed by two groups. In order to estimate the system efficiency, a follow-up test had been done the health promoting behaviors for 150 days.

The contents assigned for prostatectomy patients are as follows: 1) Introduction: introduction, objective, and procedure of an integrated information system. 2) Quality: Positive changes of health condition, examination and therapeutic contents: 
just after application. 3) Motivation: disease recognition and attitude of patients. 4) Awareness: Medical research and education data 4) Change: change of health condition 5) Impact: impact of health improvement after prostatectomy 6) Effectiveness: effectiveness of the integrated information system 7) Evaluation: assessment of basic data file in patients with prostatectomy [Table 1].

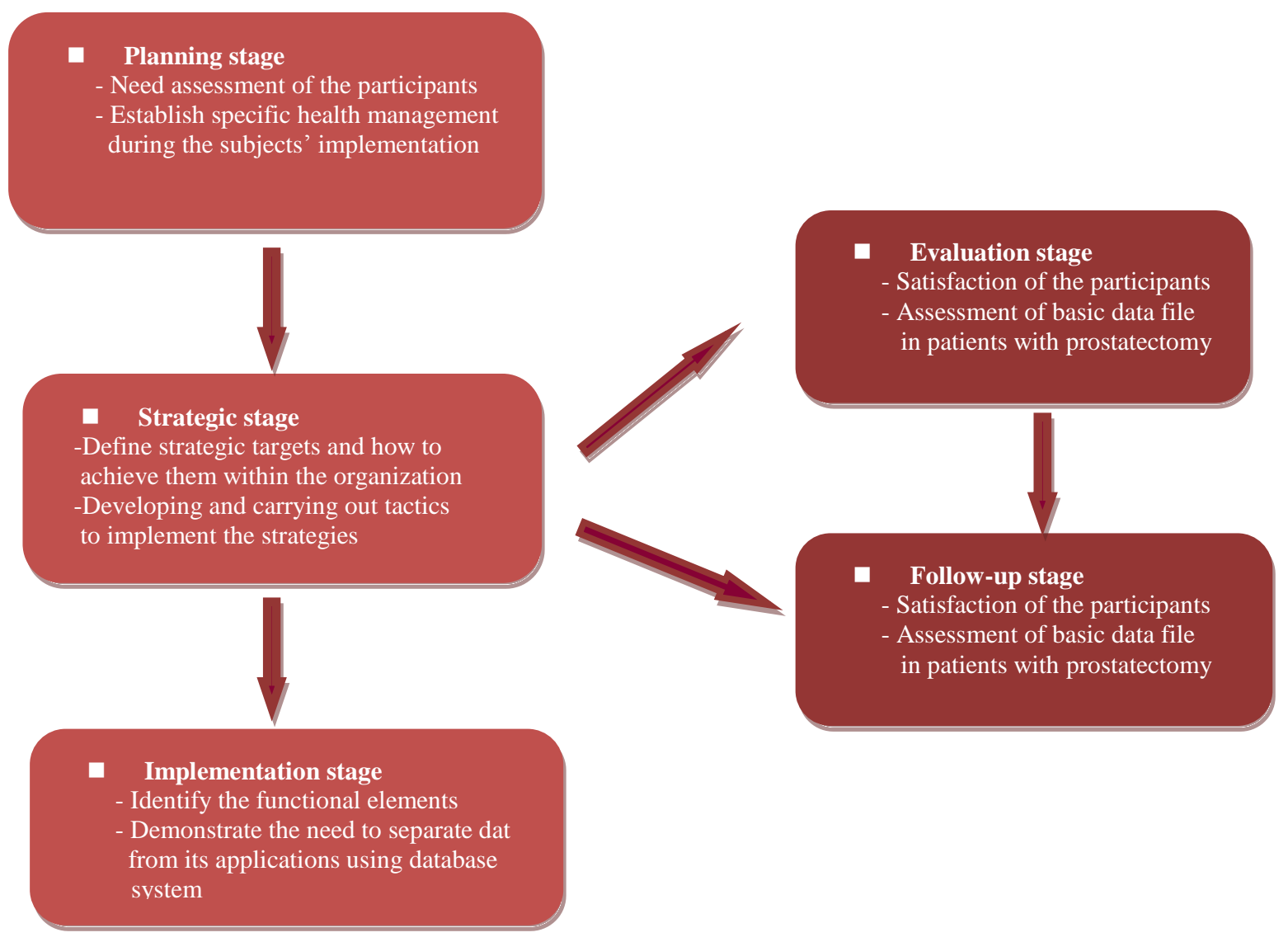

\section{Figure 1. Structure of an Integrated Information System for the Prevention of Prostate Cancer}

\subsection{Study Methods}

General characteristics of study subjects were measured by percentage and number. The $\chi^{2}$-test was used to observe a statistically significant difference between experimental and control group. The pairwise t-test was done to compare the health promoting behaviors before and after application of medical information system after radical prostatectomy. It was also performed to determine the statistical significant differences between the two groups on the satisfaction of an integrated information system for measurement of health promoting behaviors for the prevention of recurrence in prostatectomy patients.

The collected data were examined the distribution of prostatectomy patient's characteristics using SPSS 18.0. Data analysis of t-test was performed with the level of statistical significance for testing at $0.05 \%$. 
Table 1. Contents Assigned for Prostatectomy Patients

\begin{tabular}{|c|c|}
\hline Division & Contents \\
\hline Introduction & $\begin{array}{l}\text {-Introduction, objective, and procedure of an integrated information } \\
\text { system } \\
\text { - Effectiveness and assessment of an integrated information system }\end{array}$ \\
\hline Quality & $\begin{array}{l}\text { - Positive changes of health condition, examination and therapeutic } \\
\text { contents : just after application }\end{array}$ \\
\hline Motivation & - Disease recognition and attitude of patients \\
\hline Awareness & $\begin{array}{l}\text { - Medical research and education data } \\
\text { - Useful information for medical management } \\
\text { - Evaluation of the integrated information system quality } \\
\text { - Communication method among patients } \\
\text { - Statistical data for national health }\end{array}$ \\
\hline Change & $\begin{array}{l}\text { - Timely management as provided by information application } \\
\text { - Change of health condition }\end{array}$ \\
\hline Feasibility & $\begin{array}{l}\text { - Impact of health improvement after prostatectomy } \\
\text { - Feasibility of the integrated information system after application to } \\
\text { patients }\end{array}$ \\
\hline Impact & $\begin{array}{l}\text { - Impact of health behaviors on life habits } \\
\text { - Difference before and after application of the integrated information } \\
\text { system }\end{array}$ \\
\hline Effectiveness & $\begin{array}{l}\text { - Effectiveness of the integrated information system } \\
\text { - Improvement of patients' health due to database system }\end{array}$ \\
\hline Evaluation & $\begin{array}{l}\text { - Satisfaction of the participants } \\
\text { - Assessment of basic data file in patients with prostatectomy }\end{array}$ \\
\hline
\end{tabular}

\section{Results}

\subsection{General Characteristics of Study Subjects}

Table 2 presents general characteristics of study subjects. Age groups were divided into four groups for two groups. That is, it was divided less than 40 years, 50 to 59 years, 60 to 69 years, and 70 years old or more. The response rate of experimental group was $8.5 \%$, while the response rate of control group was $15.5 \%$ in subjects under the age of 49 years old. The response rate $(29.6 \%)$ of experimental group was statistically significantly higher than the response rate $(26.8 \%)$ in the 50 to 59 years old $\left(\chi^{2}=10.27, \mathrm{p}<.05\right)$. The response rate $(26.8 \%)$ of experimental group was lower than the response rate $(32.4 \%)$ of control group in the age of 60 to 69 years old. The response rate(35.2\%) of experimental group was higher than the response rate $(25.4 \%)$ of control group in subjects over the age of 70 years old. However, there was no significant difference for the age group between two groups. For marital status, the respondent rate $(83.1 \%)$ of experimental group was lower than the respondent rate $(85.9 \%)$ of control group, however, there was no significant difference between two groups.

On the other hand, In terms of infectious disease history, it showed higher in subjects(54.9\%) who had suffered from infectious disease in the experimental group than that of control groups(32.4\%). For voiding difficulty of urine, the response rate(87.3\%) of experimental group was statistically significantly higher than the response rate(39.4\%) of 
control group in subjects who had suffered from voiding difficulty of urine $\left(\chi^{2}=6.51\right.$, $\mathrm{p}<.01)$.

Table 2. General Characteristics of Study Subjects

\begin{tabular}{|c|c|c|c|}
\hline & Experimental group & Control group & \\
\hline Variables & $\mathrm{N}(\%)$ & $\mathrm{N}(\%)$ & $\chi^{2}$ \\
\hline \multicolumn{4}{|l|}{ Age/yrs. } \\
\hline$\leq 49$ & $6(8.5)$ & $11(15.5)$ & $10.27 *$ \\
\hline $50-59$ & 21(29.6) & $19(26.8)$ & \\
\hline $60-69$ & $19(26.8)$ & $23(32.4)$ & \\
\hline$\geq 70$ & $25(35.2)$ & $18(25.4)$ & \\
\hline \multicolumn{4}{|l|}{ Marital status } \\
\hline Single & $12(16.9)$ & $10(14.1)$ & 4.95 \\
\hline Married & $59(83.1)$ & $61(85.9)$ & \\
\hline \multicolumn{4}{|c|}{ Monthly income } \\
\hline$<200$ & $16(22.5)$ & $22(31.0)$ & 8.31 \\
\hline 200-399 & $31(43.7)$ & $28(39.4)$ & \\
\hline$\geq 400$ & $24(33.8)$ & $21(29.6)$ & \\
\hline \multicolumn{4}{|l|}{$\operatorname{BMI}\left(\mathrm{Kg} / \mathrm{m}^{2}\right) \dagger$} \\
\hline$<18.5$ & $22(31.0)$ & $19(26.8)$ & 5.74 \\
\hline $18.5-22.9$ & $19(26.8)$ & $25(35.2)$ & \\
\hline$\geq 23.0$ & $30(42.3)$ & $27(38.0)$ & \\
\hline \multicolumn{4}{|l|}{ Education level } \\
\hline $\begin{array}{l}\text { Under middle } \\
\text { school }\end{array}$ & $14(19.7)$ & $18(25.4)$ & \\
\hline High school & $30(42.3)$ & $22(31.0)$ & 9.72 \\
\hline Over college & $27(38.0)$ & $31(43.7)$ & \\
\hline \multicolumn{4}{|l|}{ Vasectomy } \\
\hline Yes & $33(46.5)$ & $27(38.0)$ & 3.64 \\
\hline No & $38(53.5)$ & $44(62.0)$ & \\
\hline \multicolumn{4}{|c|}{$\begin{array}{l}\text { Infectious disease } \\
\text { history }\end{array}$} \\
\hline Yes & $39(54.9)$ & $23(32.4)$ & 5.09 \\
\hline No & $32(45.1)$ & $48(67.6)$ & \\
\hline \multicolumn{4}{|l|}{$\begin{array}{l}\text { Cancer family } \\
\text { history }\end{array}$} \\
\hline Yes & $28(39.4)$ & $20(28.2)$ & 8.29 \\
\hline No & $43(60.6)$ & $51(71.8)$ & \\
\hline \multicolumn{4}{|l|}{$\begin{array}{l}\text { Voiding } \\
\text { difficulty }\end{array}$} \\
\hline Yes & $62(87.3)$ & $28(39.4)$ & $6.51 * *$ \\
\hline No & $9(12.7)$ & $43(60.6)$ & \\
\hline Total & $71(100.0)$ & 71(100.0) & \\
\hline
\end{tabular}




\subsection{Health Behaviors after Application of an Integrated Information System}

Table 3 represents health behaviors before and after application of an integrated information system. In terms of voiding difficulty, subjects' score(41.75 \pm 1.62$)$ after application significantly decreased than subjects $(69.31 \pm 1.28)$ before application $(t=1.93$, $\mathrm{p}=.000$ ). On the other hand, for dietary factors, there was a significant difference in practicing the healthy lifestyle of tomato intake after application of the integrated information $\operatorname{system}(\mathrm{t}=-3.82, \mathrm{p}=.000)$. On the other hand, for PSA level, it was much lower after application as compared with before application in the experimental group $(\mathrm{t}=3.61$, $\mathrm{p}=.007$ ).

\section{Table 3. Health Behaviors after Application of an Integrated Information System}

\begin{tabular}{lcccc}
\hline & Before & After & & \\
\cline { 2 - 3 } Items & Mean \pm S.D & Mean \pm S.D & $\mathrm{t}$ & $\mathrm{P}$ \\
\hline Physical factors & & & & \\
Voiding difficulty & $69.31 \pm 1.28$ & $41.75 \pm 1.62$ & 1.93 & .000 \\
Sexual life & $31.79 \pm 1.65$ & $36.18 \pm 1.39$ & -0.57 & .316 \\
Urinary frequency & $67.54 \pm 0.83$ & $52.93 \pm 0.51$ & 2.62 & .059 \\
Stress & $72.36 \pm 1.59$ & $56.37 \pm 2.83$ & 1.39 & .000 \\
Obesity control & $61.82 \pm 0.17$ & $47.82 \pm 0.75$ & 0.88 & .024 \\
Exercise & $35.17 \pm 1.39$ & $69.15 \pm 1.92$ & -1.47 & .000 \\
Dietary factors & & & & \\
Tomato intake & $39.45 \pm 1.72$ & $65.40 \pm 1.69$ & -3.82 & .000 \\
Soybean intake & $31.24 \pm 0.35$ & $62.72 \pm 0.85$ & -0.57 & .000 \\
Vegetable intake & $45.96 \pm 1.84$ & $73.58 \pm 1.27$ & -1.74 & .000 \\
Smoking & $58.16 \pm 1.57$ & $31.62 \pm 2.69$ & 4.92 & .000 \\
Alcohol drinking & $64.72 \pm 0.96$ & $47.59 \pm 1.55$ & 0.58 & .001 \\
Clinical factors & & & & .600 \\
Diabetes mellitus & $42.17 \pm 1.48$ & $39.52 \pm 1.53$ & 3.76 & .629 \\
Hypertension & $62.52 \pm 0.73$ & $54.29 \pm 0.81$ & 1.54 & .317 \\
Cholesterol & $57.11 \pm 0.52$ & $51.84 \pm 0.20$ & 0.82 & .543 \\
PSA level $\dagger$ & $64.26 \pm 0.37$ & $45.19 \pm 0.72$ & 3.61 & .007 \\
\hline
\end{tabular}

$\dagger$ PSA : Prostate-specific antigen

\subsection{Changes of Physical Factors As the Time Elapsed Between Two Groups}

Figure 2 shows the changes of physical factors as the time elapsed between two groups before and after application of an integrated information system. The follow-up survey showed higher level in the experimental group than the control group, regardless of the time elapsed of 30 days after application as compared with previous status. However, experimental group showed a little decrease as time elapsed of 90 days in the experimental group after application. 


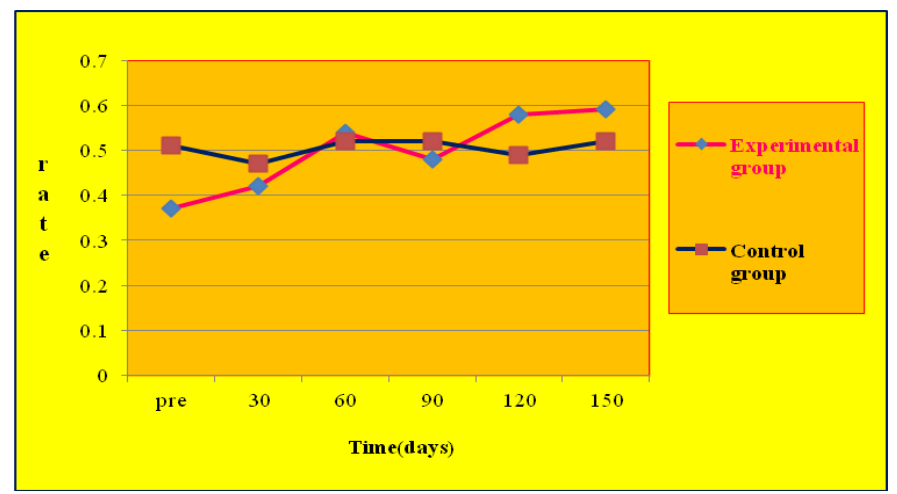

Figure 2. Changes of Physical Factors As the Time Elapsed Between Two Groups

\author{
*Slope $=\triangle \underline{\triangle Y} \quad$ Where $\triangle \mathrm{X}:$ time interval \\ $\triangle \mathrm{Y}$ : variation of health practice \\ *Ratio $=\triangle \mathrm{Ya}$ Where $\triangle \mathrm{Yb}:$ health behaviors before an integrated information application \\ $\triangle \mathrm{Yb} \quad \triangle \mathrm{Ya}:$ health behaviors after an integrated information applciton
}

\title{
3.4. Changes of Physical Factors As the Time Elapsed Between Two Groups
}

Figure 3 shows the changes of dietary factors as the time elapsed between between two groups before and after application of an integrated information system. The follow-up survey showed higher level in the experimental group than the control group, regardless of the time elapsed of 30 days after application as compared with previous status. However, experimental group showed rapidly decrease as time elapsed of 60 days in the experimental group after application.

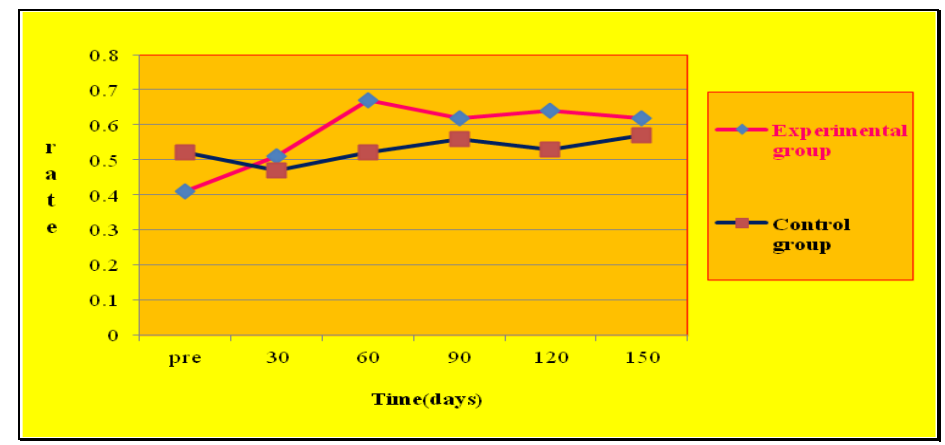

Figure 3. Changes of Dietary Factors as the Time Elapsed between Two Groups

\footnotetext{
$*$ Slope $=\triangle \underline{\triangle Y} \quad$ Where $\triangle \mathrm{X}:$ time interval

$\triangle \mathrm{Y}$ : variation of health practice

*Ratio $=\triangle \mathrm{Ya}$ Where $\triangle \mathrm{Yb}:$ health behaviors before an integrated information application

$\triangle \mathrm{Yb} \quad \triangle \mathrm{Ya}:$ health behaviors after an integrated information applciton
} 


\title{
3.5. Changes of Clinical Factors As the Time Elapsed Between Two Groups
}

Figure 4 shows the changes of clinical factors as the time elapsed between two groups before and after application of an integrated information system. The follow-up survey showed higher level in the experimental group than the control group, regardless of the time elapsed of 30 days after application as compared with previous status. However, experimental group showed a little decrease as time elapsed of 120 days in the experimental group after application.

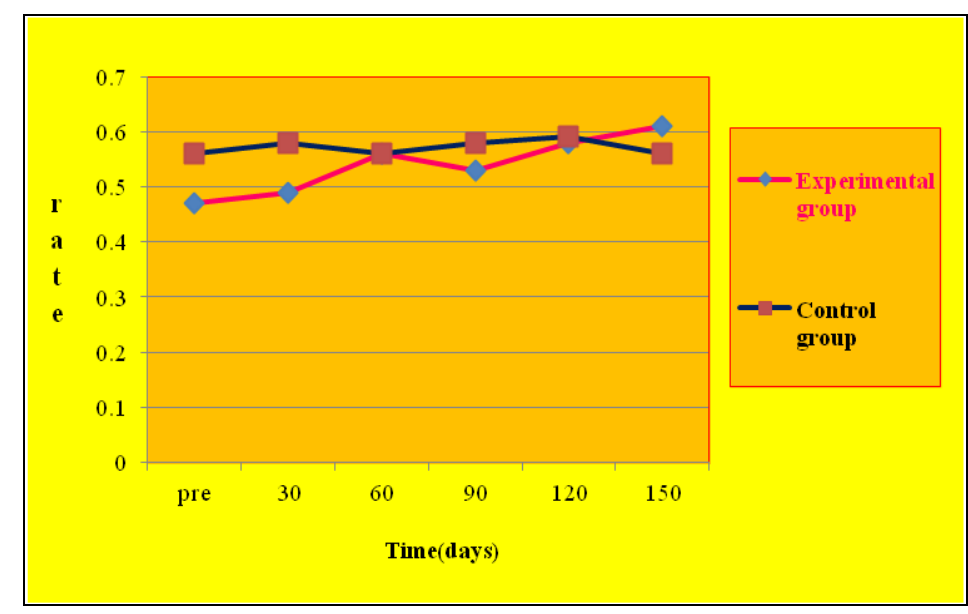

\section{Figure 4. Changes of Clinical Factors as the Time Elapsed Between Two Groups}

\author{
*Slope $=\frac{\triangle Y}{\triangle X}$ Where $\triangle X:$ time interval \\ $\triangle \mathrm{Y}$ : variation of health practice \\ *Ratio $=\triangle \mathrm{Ya}$ Where $\triangle \mathrm{Yb}:$ health behaviors before an integrated information application \\ $\triangle \mathrm{Yb} \triangle \mathrm{Ya}:$ health behaviors after an integrated information applciton
}

\subsection{Comparison of User Satisfaction on an Integrated Information System}

Table 4 represents comparison of user satisfaction on an integrated information system after application of the information system between two groups. For efficiency of the integrated information system, the mean score of subjects who was fast to search the information was $26.42 \pm 0.39$ in experimental group and was $34.18 \pm 0.29$ in control group, respectively. There was significantly lower in experimental group $(\mathrm{t}=-2.93, \mathrm{p}=.035)$ than control group. For recommendation of the information system, there was a significant difference between two groups for recommendation of the information system to other persons $(\mathrm{t}=1.63, \mathrm{p}=.042)$. 
Table 4. Comparison of User Satisfaction on an Integrated Information System

\begin{tabular}{|c|c|c|c|c|}
\hline Items & $\begin{array}{c}\begin{array}{c}\text { Experimental } \\
\text { group }\end{array} \\
\text { Mean } \pm \text { S.D. }\end{array}$ & $\begin{array}{l}\begin{array}{l}\text { Control } \\
\text { group }\end{array} \\
\text { Mean } \pm \text { S.D. }\end{array}$ & $\mathrm{t}$ & $\mathrm{P}$ \\
\hline \multicolumn{5}{|c|}{$\begin{array}{l}\text { Feasibility of an integrated information } \\
\text { system }\end{array}$} \\
\hline Easy to use information system & $31.18 \pm 0.27$ & $36.25 \pm 0.61$ & -1.48 & .284 \\
\hline Easy to contact to operator & $37.52 \pm 1.39$ & $34.78 \pm 0.57$ & 3.52 & .629 \\
\hline \multicolumn{5}{|c|}{$\begin{array}{l}\text { Efficiency of an integrated information } \\
\text { system }\end{array}$} \\
\hline Easy to connect system & $35.67 \pm 0.54$ & $39.25 \pm 1.36$ & -4.27 & .573 \\
\hline Fast to search information & $26.42 \pm 0.39$ & $35.18 \pm 0.29$ & -2.93 & .035 \\
\hline \multicolumn{5}{|c|}{$\begin{array}{l}\text { Usefulness of an integrated information } \\
\text { System }\end{array}$} \\
\hline $\begin{array}{l}\text { Useful information of health } \\
\text { Improving behaviors }\end{array}$ & $39.16 \pm 1.35$ & $37.43 \pm 0.51$ & 3.52 & .612 \\
\hline Easy to understand & $30.82 \pm 0.93$ & $34.92 \pm 1.64$ & -1.47 & .595 \\
\hline \multicolumn{5}{|l|}{$\begin{array}{l}\text { Recommendation of an integrated } \\
\text { information system }\end{array}$} \\
\hline $\begin{array}{l}\text { Recommendation to other } \\
\text { persons }\end{array}$ & $38.17 \pm 0.25$ & $29.58 \pm 1.39$ & 1.63 & .042 \\
\hline Detailed contents & $37.42 \pm 1.49$ & $32.72 \pm 1.62$ & 4.29 & 194 \\
\hline
\end{tabular}

\section{Discussion}

The purpose of this study was to investigate the effects of an integrated information system application to improve health behaviors after prostatectomy.

As a result of this study, there were statistically significantly positive changes of health status such as voiding difficulty, tomato intake, and obesity control. It diminished the progression rate of prostatectomy patients. The findings were similar to the previous studies on the other operation patients $[6,18]$. This study suggests that individuals with prostatectomy patients should be targeted for specific health improving behaviors for the prostate cancer patients. However, in order to maintain desirable food behaviors, convergence educational program for prostatectomy patients focused on health promoting behavior is more successful than single program.

The results of this paper, after receiving intervention, there was a positive change for physical factors after intervention than before intervention in the mean score of stress status. The finding was consistent with the result of earlier researches $[11,19]$. Therefore, it needs to perform systematic stress management.

The result of laboratory after apply the integrated information system, there has been a significant decrease at PSA level. The finding is similar to previous studies on the prostate cancer $[13,20]$. Prostate-specific antigen (PSA) is a glycoprotein derived from prostatic ductal and acinar epithelial cells and the most commonly used tumor marker for prostate cancer, in the monitoring of recurrence as well as in diagnosis.

This study showed a positive change in experimental groups who underwent radical prostatectomy. It revealed positive tumor cells for PSA and PAP (prostate acid phosphatase). After 2 months of hormonal therapy including anti-androgen and gonadotropin releasing hormone agonist, the multiple metastatic nodules showed nearly complete regression. However, several studies have reported that metastases of prostate adenocarcinoma can occur despite normal serum PSA level, and if clinically warranted, the immunohistochemical staining or other serologic marker for the prostate 
adnocarcinoma should be considered in the evaluation of metastatic carcinoma of unknown primary in male although the serum PSA is not elevated.

After the experiment, the experimental group which experienced patients' information application level on an integrated information system showed the effectiveness of improvement of health improving behaviors in prostatectomy patients. Therefore, a comprehensive and systematic adoption of the medical system to minimize the damage of prostate cancer will contribute effectively to the rapid disease recovery and prevention.

In the future, this experimental study will be used frequently for the prevention of prostate cancer and verification of new research. Thus, efficient and error-free information system for handling personalized medical history and test results are infallibly necessary. In this paper, I have proposed an integrated information system for informatization of prostatectomy patients that support the healthcare environment based on application. The proposed system supports systematization of whole application process and information of health promoting system.

This an integrated information system will contribute to reduction of costs, improvement of operational efficiency, and mostly fundamental prevention of prostate cancer. The proposed information-based integrated medical information system will also contribute to solve the problems of current information systems by enabling integration of separated information and by allowing data exchange and sharing through internet. The proposed system with application is more efficient than web-based medical information system. Because this integrated information system itself provides more flexibility and extensibility than previous information system.

\section{Conclusion}

This paper is to design an efficient integrated information system to enhance health improving behaviors after radical prostatectomy. The results of this study are as follows.

First, for voiding difficulty of urine, the response rate(87.3\%) of experimental group was statistically significantly higher than the response rate $(39.4 \%)$ of control group in subjects who had suffered from voiding difficulty of urine $\left(\chi^{2}=6.51, p<.01\right)$.

Second, for soybean intake, positive change of health behaviors diminished the progression rate of prostate cancer $(31.24 \pm 0.35, \mathrm{t}=-0.57, \mathrm{p}=.000)$.

Third, this paper found that the health promoting behaviors in prostate cancer patients was increased by $69.2-73.6 \%$ compared with the previous status.

Four, for clinical factors, the follow-up survey showed higher level in the experimental group than the control group, regardless of the time elapsed of 30 days after application as compared with previous status. However, experimental group showed a little decrease as time elapsed of 120 days in the experimental group after application.

Five, for the recommendation to other persons, the patients significantly positively perceived on the integrated information $\operatorname{system}(\mathrm{t}=1.63, \mathrm{p}=, 042)$.

In conclusion, this paper conducted a positive effect on health enhancement of prostatectomy patients. This paper also showed the feasibility of the integrated information system through some tests. Moreover, this paper showed that health improving behaviors using the integrated information system as health practice tool was a good way to enhance the practice rate of health behavior in prostatectomy patients. Thus, the paper can use the results as guidelines for designing health behavior and networks. 


\section{Acknowledgment}

I would like to express my deepest appreciation to study subjects who have participated in development of the structure model of an integrated information system and empirical application for the health promoting behaviors after radical prostatectomy in a busy life. The experimental model will provide effective services in multi-environments to patients with prostate cancer and help in improving their health conditions of radical prostatectomy patients. In addition, the model application in prostatectomy patients will be widely used as an effective treatment guide.

This paper is a revised and expanded version of a paper entitled "A Design of Efficient Medical Information System to Enhance Health Behaviors After Radical Prostatectomy," presented at "The 3rd International Conference on Medical, Medicine and Health Science (MMHS 2014)," held on October 24-26, 2014 at Liberty Central Saigon Hotel, Hochimin, Vietnam.

\section{References}

[1] Statistics Korea, "Annual Report on the Cause of Death Statistics", (2013), pp. 13-15.

[2] Korean Urological Association, "Urology", (2007).

[3] S.R. Lee, "The Application Efect of A Medical Information Management System for the Prevention of Depression in Mastectomy Patients", IJBSBT, vol. 5, no. 5, (2013).

[4] J.T. Wei, R.I. Dunn, H.M. Sandler, P.W. McLauhlin, J.E. Montie and M.S. Litwin, "Comprehensive Comparison of Health-related QOL After Contemporary Therapies for Localized Prostate Cancer", J Clin Oncol, vol. 20, no. 201, (2002).

[5] D.S. Channin, "Integrating the Healthcare Enterprise, A Primer 6, The Followship of IHE : Year 4 Additions and Extensions", Radiographics, vol. 22, no. 1555-1556, (2002).

[6] C. Loet, "Evidence and Diagnostic Reporting in the IHE Contex", International Congress Series, (2004), pp.108-112.

[7] S.M. Moore, "Using the IHE Scheduled Workflow Integration Profile to Drive Modality Efficiency", Radiographics, vol. 23, no. 523, (2003).

[8] R. P. Zambuto, "IHE Educational Workshop for Vendors and Implementers", IHE Workshop 2007 : Changing the Way Healthcare Connects, vol. 11, no. 13, (2007).

[9] E.L. Siegel, D.S. Channin, "Integrating the Health Care Enterprise : A Primer, Introduction Radiographics", vol. 21, no. 1339, (2001).

[10] L.M. Rondorf-Klym and J. Colling, "Quality of Life Another Radical Prostatectomy, Oncol. Nurs. Forum, vol. 30, no. 2, (2003).

[11] S.R. Lee, Short-Term Impact Analysis of A Clinical Information System Adoption on Relieving Menstrual Distress in Women, IJBSBT, 5, 61, 68 (2014)

[12] D.F. Penson, Z. Feng, A. Kuniyuki, O. McClerran, P.C. Albertsen and D. Dapen, "General Quality of Life 2 years Following Treatment for Prostate Cancer", What Influences Outcomes? Results from the Prostate Cancer Outcomes Study, J Clin Oncol, vol. 21, no. 6, (2003).

[13] A. Jun, "Multi-granularity Locking-based Concurrency Control in Object-Oriented Database Systems", Journal of Systems and Software, vol. 54, no. 201, (2000).

[14] S. R. Lee, "Design of Efficient Medical Information System to Enhance Health Behaviors After Radical Prostatectomy", The $3^{\text {rd }}$ International Conference on Next Generation Computer and Information Technology, (2014); Hochimin, Vietnam.

[15] S. A. Brassel, D.I. Elsamanoudi, J. Cullen, M.C. Williams and D.G. McLeod, "Health-related Quality of Life for Men with Prostate Cancer : An Evaluation of Outcomes 12-24 Months After Treatment", Urol, Oncol, vol. 31, no. 81, (2013).

[16] P. Taxel. M.C. Stevens, M. Trahiotics, J. Zimmerman and R.F. Kaplan, "The Effect of Short-Term Estradiol Therapy on Cognitive Function in Older Men Receiving Hormonal Suppression Therapy for Prostate Cancer", J Am Geriat Soc, vol. 52, no. 2, (2004).

[17] S. R. Lee, "The Effect of An Integrated Information System Adoption for Performance Ability Improvement in Hypertensive Patients", IJSEIA, vol. 8, no. 3, (2014).

[18] E. J. Moore, "Using Self-Efficacy in Teaching Self-Care to the Elderly", vol.4, no. 22, (2010).

[19] R. Susan, S. P. Levy and C. Rasher, "Relation of Intensity and Frequency of Student Drug Use to Reasons for Use", The Journal of School Health, vol. 51, no. 343, (2005).

[20] S.R. Lee, "The Model Development and Empirical Application for the Alleviation of Low Back Pain", The $5^{\text {th }}$ International Conference Ubiquitous Computing and Multimedia Application, (2014); Indonesia. 


\section{Author}

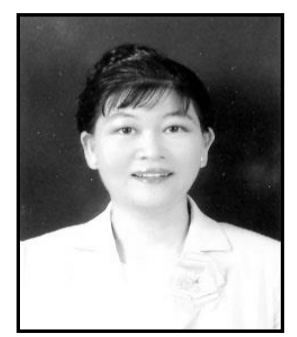

Seong-Ran Lee received the B.S. degree in consumer science from Seoul National University, Korea in 1987. She received the M.S. degree in health science from Seoul National University, Korea in 1992 and Ph.D in the same area from Catholic Medical College, Seoul, Korea in 2000. Currently, she is a professor in the department of medical information, Kongju National University, Korea. Her present research interest is an information system. 